\title{
Use of Q methodology to assess the concerns of adult female individuals seeking orthodontic treatment
}

Linjie Yao'

Xingqiao $\mathrm{Xu}^{2}$

Zhenyu $\mathrm{Ni}^{3}$

Minling Zheng ${ }^{3}$

Feiou $\operatorname{Lin}^{3}$

'Department of Pedodontics,

${ }^{2}$ Department of Oral and Maxillofacial Surgery, ${ }^{3}$ Department of Orthodontics, School and Hospital of Stomatology, Wenzhou Medical University, Wenzhou, People's Republic of China
Correspondence: Feiou Lin Department of Orthodontics, School and Hospital of Stomatology, Wenzhou Medical University, I I 3 Xue Yuan West Road, Lu Cheng District, Wenzhou, Zhejiang 325027, People's Republic of China

Tel +8657788063012

Fax +86 57788063666

Email linfeiousci@।63.com
This article was published in the following Dove Press journal:

Patient Preference and Adherence

8 January 2015

Number of times this article has been viewed

Background: Orthodontic treatment may cause functional restrictions, discomfort, and pain, which may lead to dental anxiety and noncooperation among patients. This study aimed to assess the concerns of adult female patients with respect to such treatment.

Patients and methods: We conducted an explorative study using Q methodology among 40 adult female patients with different educational and social backgrounds in Wenzhou, People's Republic of China. We asked participants to rank a set of 41 statements about seeking orthodontic treatment on an 11-point scale from "agree most" to "disagree most". The collected data were analyzed using the PQ Method 2.35 program. We extracted significant viewpoints using centroid factor extraction and varimax rotation.

Results: We identified major factors based on how the patients ranked statements. Patients in group 1 worried about lack of information about orthodontic treatment, and may have suffered from dental phobia; patients in group 2 were all single women, and they were worried that the braces might lower their chances of finding a partner; patients in group 3 worried about appearance and speech with braces; and patients in group 4 worried about cost, pain, and dental hygiene. The remaining participants who had other viewpoints did not load to any of these four groups.

Conclusion: The concerns of adult female individuals seeking orthodontic treatment are complex. A significant feature of this study was using Q methodology to analyze the psychological characteristics of the patients. This study identified four typical characterizations that are associated with each group, and our findings may aid orthodontists in improving doctorpatient relationships.

Keywords: orthodontic treatment, Q methodology, adult female patient

\section{Introduction}

A person's oral condition can affect their physical, psychological, and social health. ${ }^{1}$ Orthodontic treatment can improve an individual's appearance, oral function, psychosocial well-being, and quality of life..$^{2-4}$ Care and attention during orthodontic treatment have been found to show a positive correlation with treatment satisfaction. ${ }^{5}$ Sergl et al highlighted a strong interrelationship between a patient's attitude at the beginning of orthodontic treatment, their ability to accommodate the discomfort associated with an orthodontic appliance, the type and intensity of discomfort encountered, and the resulting overall compliance with the treatment. ${ }^{6}$ However, orthodontic treatment and appliances may cause functional limitations, discomfort, and pain, ${ }^{7-9}$ which may lead to dental anxiety. ${ }^{10}$ It has been reported that patients' lack of information about the risks of orthodontic treatment or fear about pain and discomfort could adversely affect their compliance during treatment. ${ }^{10-12}$ Studies have shown that the number of 
adults - especially women - seeking orthodontic treatment has increased, ${ }^{13,14}$ and aesthetics is one of the most important motivations for patients in seeking orthodontic treatment. ${ }^{15}$ The demand for adult orthodontic treatment has grown rapidly in recent years. It is necessary to understand the psychological characteristics and motives of adult patients, since these factors may affect a patient's satisfaction and adherence to treatment. ${ }^{16}$ However, there is a lack of research into the factors that deter adult female patients from seeking orthodontic treatment.

Most studies on orthodontic patients' subjective perspectives have used surveys, such as oral health and anxiety questionnaires, to collect attitude data from patients, and in the case of pediatric patients, their parents..$^{2-5,9-12}$ Conventional survey studies on subjective perspectives have three major disadvantages. First, it is well established that such studies require a great investment of manpower, as well as physical and financial resources, owing to the large sample size. Second, such survey items often treat subjective perspectives in an isolated fashion, disconnected from other such perspectives. Participants respond to each subjective perspective independently, which reduces variability in the survey responses and impedes relative differentiation among those perspectives. Third, social desirability in survey responses has been a long-standing drawback, particularly with sensitive issues.

By contrast, the $\mathrm{Q}$ method combines qualitative and quantitative methodologies, and it provides a scientific foundation for the systematic study of subjectivity. ${ }^{17}$ It is a research method that allows the systematic review of subjective perspectives, and it is especially relevant for communication scientists whose research involves the perceptual world of individuals. ${ }^{18}$ The Q method typically employs small numbers of respondents, and it allows the in-depth study of single cases, which is typically lacking in conventional survey methods. Another major advantage of Q methodology over traditional methods is that it uses a person-oriented instead of variablebased approach, wherein attitudes are treated as components of larger within-person perspectives rather than as discrete items. ${ }^{19} \mathrm{Q}$ methodology precludes the inevitable social desirability issue that is inherent in conventional survey responses. As such, Q methodology may be used in any international or cultural context for effective study of the participants' subjectivity, even where there are marginal views or attitudes. ${ }^{20}$ Q methodology has been used in social sciences, arts, religious studies, education, psychology, and medicine; in the field of orthodontics, it has been employed in three studies. $^{21,22}$
The present study used Q methodology to assess the concerns of adult females with respect to orthodontic treatment. The purpose was to develop an effective strategy that could improve patient satisfaction and adherence to treatment. We also aimed to help patients avoid dental anxiety in terms of the factors to which they were most sensitive.

\section{Patients and methods}

This was a prospective interview study with a nonrandom design. The subjects were recruited between January and July 2014 from the orthodontic department of Wenzhou Medical University, Wenzhou, People's Republic of China (PRC). The study included adult female patients above 18 years of age. Patients with cleft lip or palate, craniofacial syndromes, orthognathic or prosthodontic needs, and amentia were excluded, because they are not representative of the typical orthodontic population. Ethics approval for the study was granted by the Health Research Ethics Board at Wenzhou Medical University, and all the subjects signed a consent form for participation.

\section{Step I: Construction of $Q$ sample}

Q sampling begins with developing the concourse, which involves collecting a wide range of attitudes on the topic under investigation. The present study was designed to construct a Q sample by interviewing the selected participants. To this end, one investigator was trained in the process of in-depth interviewing. The interviews generated a list of viewpoints about the concerns of adult female patients when seeking orthodontic treatment, in addition to their general concerns. We interviewed 112 patients of all ages and backgrounds during their first visit to the orthodontic department. From this interview material, we compiled a list of 69 viewpoints; two professors of orthodontics and two methodologists discussed the statements and identified areas of overlap. We finally created a list of 41 statements (Q sample), which comprised the concourse.

\section{Step 2: P sample selection}

With Q methodology, participant selection does not depend on probability sampling. ${ }^{23}$ Typically, breadth and diversity of attitudes is best obtained when a participant group contains between 40 and 60 participants. The number of participants is usually but not necessarily smaller than the Q sample. However, good results can be achieved with far fewer participants. ${ }^{18,19}$ We were able to recruit 40 adult female patients using our selection criteria, and their demographics appear in Table 1. 
Table I Demographics of P sample

\begin{tabular}{ll}
\hline Demographic & P sample, n (\%) \\
\hline Age, years & $15(37.5)$ \\
$18-24$ & $20(50.0)$ \\
$25-30$ & $5(12.5)$ \\
$>30$ & \\
Level of education & $6(15.0)$ \\
Illiterate/primary school & $10(25.0)$ \\
Secondary school & $24(60.0)$ \\
Tertiary & \\
Region & $21(52.5)$ \\
Urban & $19(47.5)$ \\
Rural & \\
Employment status & $6(15.0)$ \\
Student & $6(15.0)$ \\
Unemployed & $28(70.0)$ \\
Employed & \\
Marital status & $28(70.0)$ \\
Single & $12(30.0)$ \\
Married & 40 \\
Total &
\end{tabular}

\section{Step 3: Q-sorting}

Every participant received a stack of 41 Q-sample cards (related to the 41 statements from step 1) as well as a sorting-instruction sheet, on the reverse side of which was a form allowing the participants to enter their demographic information. The participants were instructed first to read all the Q statements to ensure that they understood them. They were then asked to sort the cards into three piles according to their reaction to the statements: agree, disagree, or uncertain. The participants subsequently ranked the statements on an 11-point scale (Figure 1). They were asked to place the statements they felt were the most relevant to them in the far-left column $(+5)$ indicated in Figure 1 and the least relevant statements in the far-right column (-5). They then worked through the remaining columns by choosing the remaining statements in terms of most and least relevance to them. This process was repeated until any remaining statements were placed in the neutral central column (0). Participants were asked to take as much time as they needed until they were happy with the sorting results. To improve the validity of the results in this study, the patients conducted the sorting in the presence of researchers, and the Q-sorting process was repeated 2 weeks later. ${ }^{18}$

\section{Statistical analysis}

We used PQ Method 2.35 to analyze the Q-sort data. We extracted the remarkable statements using centroid factor extraction and varimax rotation. We compared the rotations of three to six factors and chose the best solution: we extracted factors that represented at least four defining sorts and had eigenvalues greater than $1 .{ }^{18}$ We created a $\mathrm{Q}$ sort for each of those factors, and those Q sorts had essentially the same form; we could then derive an overall Q grid for the typical participant profile that loaded to a particular factor. The agreement or disagreement with the distinguishing statements was statistically stronger with some factors than with others. Distinguishing statements that are significant at $P<0.05$ are indicated with a single asterisk, and those at $P<0.01$ with a double asterisk.

\section{Results}

Analysis of the participants' Q sorts resulted in the identification of four factors (Figures 1-4): factor 1 (21.62\%), factor $2(12.26 \%)$, factor $3(9.38 \%)$, and factor $4(7.90 \%)$. Cumulatively, those extracted factors accounted for $51.16 \%$ of all the variance (Table 2), and the eigenvalues of each factor were $6.05,3.43,2.63$, and 2.21 , respectively. Those four factors were defined by 32 adult patients $(80.0 \%)$; three participants did not have a statistically significant load on any of the factors, and five participants were confounded. The sociodemographic characteristics of the participants appear in Table 2, and all the distinguishing statements in Table 3.

\section{Factor 1}

\begin{tabular}{|c|c|c|c|c|c|c|c|c|c|c|}
\hline Agree & Most & & & & & & & & Disagree & Most \\
\hline+5 & +4 & +3 & +2 & +1 & 0 & -1 & -2 & -3 & -4 & -5 \\
\hline S31 & $\mathrm{S} 19^{* *}$ & $\mathrm{~S} 28^{* *}$ & $\mathrm{~S} 15^{\star}$ & S40 & S4 & s1 & $\mathrm{S} 21^{* *}$ & $\mathrm{~S} 22$ & $S 9^{* *}$ & $\mathrm{~S} 23$ \\
\hline \multirow[t]{4}{*}{ S26 } & $\mathrm{S} 30^{*}$ & $\mathrm{~S} 17$ & S $32^{* *}$ & $S 7^{* *}$ & S6 & $\mathrm{S} 12$ & $\mathrm{~S} 11$ & S5 & $\mathrm{S} 2$ & S34 \\
\hline & $\mathrm{S} 29$ & $\mathrm{~S} 27^{* *}$ & S $38^{* *}$ & $\mathrm{~S} 25^{\star *}$ & S14 & $\mathrm{S} 16^{* *}$ & $\mathrm{~S} 10$ & S8 & $\mathrm{S} 24$ & \\
\hline & & S36 & S3 & S35* & S33* & $\mathrm{S} 18^{* *}$ & $\mathrm{~S} 13$ & S $39^{* *}$ & & \\
\hline & & & & S37 & S41 & $\mathrm{S} 20$ & & & & \\
\hline
\end{tabular}

Figure I Q grid for factor I.

Notes: *Distinguishing statement significant at $P<0.05$; **distinguishing statement significant at $P<0.0$ I. 


\section{Factor 2}

\begin{tabular}{lllllllllll} 
Agree & Most & & & & & & & & Disagree & Most \\
\hline 5 & +4 & +3 & +2 & +1 & 0 & -1 & -2 & -3 & -4 & -5 \\
$\mathrm{~S} 27^{\star *}$ & $\mathrm{~S} 16$ & $\mathrm{~S} 1^{* *}$ & $\mathrm{~S} 4$ & $\mathrm{~S} 2^{* *}$ & $\mathrm{~S} 3^{*}$ & $\mathrm{~S} 7$ & $\mathrm{~S} 12$ & $\mathrm{~S} 8$ & $\mathrm{~S} 11^{*}$ & $\mathrm{~S} 21$ \\
$\mathrm{~S} 39^{* *}$ & $\mathrm{~S} 26$ & $\mathrm{~S}^{* *}$ & $\mathrm{~S} 9^{* *}$ & $\mathrm{~S} 10^{*}$ & $\mathrm{~S} 14$ & $\mathrm{~S} 24^{*}$ & $\mathrm{~S} 36^{* *}$ & $\mathrm{~S} 25^{* *}$ & $\mathrm{~S} 20$ & $\mathrm{~S} 35^{* *}$ \\
& $\mathrm{~S} 31$ & $\mathrm{~S} 13^{*}$ & $\mathrm{~S} 18$ & $\mathrm{~S} 15$ & $\mathrm{~S} 15$ & $\mathrm{~S} 30^{* *}$ & $\mathrm{~S} 40^{* *}$ & $\mathrm{~S} 28^{* *}$ & $\mathrm{~S} 23$ & \\
& & $\mathrm{~S} 29$ & $\mathrm{~S} 19$ & $\mathrm{~S} 37$ & $\mathrm{~S} 34$ & $\mathrm{~S} 38$ & $\mathrm{~S} 33^{* *}$ & $\mathrm{~S} 6^{* *}$ & & \\
& & & & $\mathrm{~S} 22^{* *}$ & $\mathrm{~S} 41$ & $\mathrm{~S} 32$ & & & &
\end{tabular}

Figure $2 \mathrm{Q}$ grid for factor 2 .

Notes: *Distinguishing statement significant at $P<0.05$; **distinguishing statement significant at $P<0.01$.

\section{Factor I: Worries about lack of information on orthodontic treatment and dental fear}

Factor 1 accounted for $21.62 \%$ of the total variance with the $\mathrm{Q}$ sorts of the eleven participants who defined this factor. Figure 1 presents the Q-methodology grid for this factor. The factor 1 perspective focused on lack of information about orthodontic treatment and dental fear. Compared with the other groups, this group of patients showed the greatest agreement with the following statements: "I am worried about orthodontic treatment because I do not have enough knowledge in this area" (S19: 4**); "I am afraid that the treatment will affect my future chewing and eating" (S30: 4*); "I am afraid of orthodontic treatment" (S15:2*); "I am afraid of pain during tooth extraction" (S7: 1**); and "I am scared of dental procedures" (S38: $\left.2^{* *}\right)$. This group of patients declared least agreement with the following statements: "I am afraid I will look unattractive with braces" (S9: $-4 * *)$; "I am worried that the treatment time will be excessively long" (S16: $-1 * *)$; and "I am worried that braces will lower my chances of finding a partner" $\left(\mathrm{S} 39:-3^{* *}\right)$. These patients strongly and significantly agreed with Q statements S25 (1**), S35 (1*), and S27 (3**).

\section{Factor 2: Worries about marriage chances}

Eight patients showed significant loading with factor 2 . Figure 2 presents the Q-methodology grid for this factor. The patients were aged 23-30 years, and were single and childless. The factor 2 viewpoint is centered on marriage and the side effects of treatment. Compared with other groups, this group of patients showed the greatest agreement with the following statements: "I am worried that braces will lower my chances of finding a partner" (S39: 5**); "I am worried that the treatment may have some side effects" (S27: $\left.5^{* *}\right)$; "There is not enough time to undergo the treatment because I'm planning on marriage and having children" (S5: $3^{* *}$ ); and "I am afraid that this orthodontic technology may not be adequate" (S22: 1**). They declared least agreement with the following statements: "I am afraid the treatment will cause me to lose appetite" (S35: $\left.-5^{* *}\right)$; "I live far from the hospital" (S11: $-4 *)$; "I am afraid the treatment will affect my eating" (S25: $-3 * *)$; and "I am afraid that the extraction will increase the space between my teeth" (S28: $-3 * *)$.

\section{Factor 3: Worries about appearance and speech with braces}

Six patients showed significant loading with factor 3 . Figure 3 presents the Q-methodology grid for this factor. The factor 3 perspective focused on social problems caused by braces. Compared with the other groups, this group of patients showed greatest agreement with the following statements: "I am afraid I will look unattractive with braces (S9: $\left.5^{* *}\right)$; "I am afraid that the treatment will be too complicated" (S14: 5*); "I am afraid that I won't be able to speak perfectly with the braces" (S37: 4**); "I am too busy with work or study and don't

Factor 3

\begin{tabular}{|c|c|c|c|c|c|c|c|c|c|c|}
\hline Agree & Most & & & & & & & & Disagree & Most \\
\hline+5 & +4 & +3 & +2 & +1 & 0 & -1 & -2 & -3 & -4 & -5 \\
\hline$S 9^{* *}$ & S $37^{* *}$ & S36 & $\mathrm{S} 35$ & $\mathrm{~S} 30$ & S39 & S15 & $\mathrm{S} 17^{* *}$ & S38 & $\mathrm{S} 18^{* *}$ & $\mathrm{~S} 23$ \\
\hline \multirow[t]{4}{*}{$\mathrm{S} 14^{*}$} & $S 2^{* *}$ & S4 & s3 & S19 & $\mathrm{S} 28$ & S41 & $\mathrm{S} 27$ & $\mathrm{~S} 13$ & S20* & S24 \\
\hline & $\mathrm{S} 25$ & $\mathrm{~S} 11^{* *}$ & $\mathrm{~S} 16^{* *}$ & S6 & $\mathrm{S} 32^{*}$ & $\mathrm{~S} 29^{* *}$ & S34 & S22 & 21 & \\
\hline & & S10* & S33* & $\mathrm{S} 31^{*}$ & $\mathrm{~S} 26$ & S7 & S5 & S8 & & \\
\hline & & & & $\mathrm{S} 40$ & S12 & S1 & & & & \\
\hline
\end{tabular}

Figure $3 \mathrm{Q}$ grid for factor 3 .

Notes: *Distinguishing statement significant at $P<0.05$; **distinguishing statement significant at $P<0.0$ I. 


\begin{tabular}{|c|c|c|c|c|c|c|c|c|c|c|}
\hline \multicolumn{11}{|c|}{ Factor 4} \\
\hline Agree & Most & & & & & & & & Disagree & Most \\
\hline+5 & +4 & +3 & +2 & +1 & 0 & -1 & -2 & -3 & -4 & -5 \\
\hline$S 13^{*}$ & $S 6^{* *}$ & $\mathrm{~S} 17$ & S14* & S3 & S24 & S4 & $\mathrm{S} 12$ & $\mathrm{~S} 10$ & $\mathrm{~S} 2$ & $\mathrm{~S} 21$ \\
\hline \multirow[t]{4}{*}{$\mathrm{S} 16$} & $\mathrm{~S} 29$ & $\mathrm{~S} 25$ & S31* & $\mathrm{S} 18$ & S37 & $\mathrm{S} 19^{* *}$ & $\mathrm{~S} 38$ & S15 & $\mathrm{S} 22$ & S34 \\
\hline & S33* & $S 7^{* *}$ & S35 & S24* & S28 & $S 9^{* *}$ & $\mathrm{~S} 20$ & S23 & $\mathrm{S} 41^{* *}$ & \\
\hline & & $\mathrm{S} 40^{*}$ & S36 & $\mathrm{S} 1^{*}$ & S39 & S26 & $\mathrm{S} 32$ & S27 & & \\
\hline & & & & $\mathrm{S} 30$ & $\mathrm{~S} 11$ & S5 & & & & \\
\hline
\end{tabular}

Figure $4 \mathrm{Q}$ grid for factor 4 .

Notes: *Distinguishing statement significant at $P<0.05$; **distinguishing statement significant at $P<0.0$ I.

have enough time to undergo the treatment"(S2: $4 * *)$; and "I am worried about what other people think, and that would make me feel uncomfortable wearing braces" (10: $\left.3^{*}\right)$. This group of patients showed least agreement with the following statements: "I cannot afford the treatment" (S18: $-4 * *)$ and "I think I am too old for orthodontic treatment" (S17: $-2 * *)$. These patients also strongly and significantly agreed with Q statements S16 (2*), S31 (1*), and S33 (2*).

\section{Factor 4: Worries about cost, pain, and dental hygiene}

Seven patients showed significant loading with factor 4 . Figure 4 presents the Q-methodology grid for this factor. The factor 4 viewpoint is centered on cost, pain, and dental hygiene. Compared with the other groups, this group of patients showed greatest agreement with the following

Table 2 Eigenvalue, variance, and characteristics of participants $(\mathrm{n}=32)$

\begin{tabular}{lllll}
\hline Demographic & Factor I & Factor 2 & Factor 3 & Factor 4 \\
\hline Eigenvalue & 6.05 & 3.43 & 2.63 & 2.21 \\
Variance, \% & 21.62 & 12.26 & 9.38 & 7.90 \\
Age, years & & & & \\
I8-24 & 7 & 1 & 2 & 2 \\
$25-30$ & 3 & 7 & 3 & 4 \\
$>30$ & $\mathrm{I}$ & 0 & $\mathrm{I}$ & $\mathrm{I}$ \\
Level of education & & & & \\
Illiterate/primary school & 2 & 0 & 1 & 1 \\
Secondary school & 3 & 1 & 2 & 3 \\
Tertiary & 6 & 7 & 3 & 3 \\
Region & & & & \\
Urban & 5 & 4 & 1 & 5 \\
Rural & 6 & 4 & 5 & 2 \\
Employment status & & & & \\
Student & $\mathrm{I}$ & 0 & 0 & 3 \\
Unemployed & $\mathrm{I}$ & $\mathrm{I}$ & 0 & 1 \\
Employed & 9 & 7 & 6 & 3 \\
Marital status & & & & \\
Single & 7 & 8 & 4 & 4 \\
Married & 4 & 0 & 1 & 3 \\
Total & $\mathrm{II}$ & 8 & 6 & 7 \\
\hline
\end{tabular}

statements: "I think the price of the treatment is too high" (S13: 5**); "It is bothersome having to brush my teeth every time I finish eating" (S33: 4*); "I am worried about pain during orthodontic treatment" (S6: 4**); "I am afraid that food will remain stuck in my teeth after eating" (40: $\left.3^{*}\right)$; and "I am afraid of pain during tooth extraction" (S7: 3**). These patients showed least agreement with the following statements: "I am afraid the treatment will affect my performance at work" (S41: $-4 * *)$ and "I am worried about orthodontic treatment because I do not have enough knowledge in this area" (S19: $-1 * *)$.

\section{Discussion}

Q methodology offers the particular advantage of letting subjects directly express their inner thoughts. The subjects' opinions are treated as variables, and research is able to focus on the subjects' views and make an in-depth appraisal of their opinions. ${ }^{18}$ The present study employed Q methodology to determine the concerns of adult female patients seeking orthodontic treatment. Female psychological and physical characteristics are very different from males'; among adult patients, there are many more adult female patients than males at the clinic where this study was conducted, and so we elected to examine only female subjects so as to eliminate interference factors. The present study is the first to use Q methodology to determine the concerns of adult female patients seeking orthodontic treatment. We were able to categorize the patients into four groups according to their views in this regard. Our results should help enhance communications between orthodontists and patients, thereby leading to greater adherence to treatment and patient satisfaction.

With factor 1 , the patients lacked information about orthodontic treatment; they were worried that they were too old to undergo the treatment and that it might have negative effects. The statements with which these patients showed agreement indicated that they did not properly understand 
Table 3 Statements and factor scores

\begin{tabular}{|c|c|c|c|c|c|}
\hline & \multirow[t]{2}{*}{ Statements } & \multicolumn{4}{|c|}{ Factor } \\
\hline & & $\mathbf{I}$ & 2 & 3 & 4 \\
\hline$\overline{\mathrm{SI}}$ & I am hesitant all the time. & -1 & 3 *** & -1 & $I^{*}$ \\
\hline S2 & $\begin{array}{l}\text { I am too busy with work or study and don't have enough } \\
\text { time to undergo the treatment. }\end{array}$ & -4 & $I^{* *}$ & $4^{* *}$ & -3 \\
\hline S3 & I am afraid that I cannot comply with the treatment. & 2 & $0 *$ & 2 & I \\
\hline S4 & I am afraid that I may not keep the appointments. & 0 & 2 & 3 & 0 \\
\hline S5 & $\begin{array}{l}\text { There is not enough time to undergo the treatment, } \\
\text { because I am planning on marriage and having children. }\end{array}$ & -3 & 3 *** & -2 & -1 \\
\hline S6 & I am worried about pain during orthodontic treatment. & 0 & $-3^{* *}$ & I & $4 * *$ \\
\hline S7 & I am afraid of pain during tooth extraction. & $I^{* *}$ & -1 & -1 & $3 * *$ \\
\hline S8 & I think orthodontics is not very hygienic. & -3 & -3 & -3 & -4 \\
\hline S9 & I am afraid I will look unattractive with braces. & $-4 * *$ & $2^{* *}$ & $5 * *$ & $-I^{* *}$ \\
\hline SIO & $\begin{array}{l}\text { I am worried about what other people think, and that } \\
\text { would make me feel uncomfortable wearing braces. }\end{array}$ & -2 & $1 *$ & $3 *$ & -2 \\
\hline SII & My place is far from the hospital. & -2 & $-4 *$ & $3^{* *}$ & 0 \\
\hline $\mathrm{S} 12$ & $\begin{array}{l}\text { I will not feel comfortable if I wear braces, as it will } \\
\text { make me look different from others. }\end{array}$ & -1 & -2 & 0 & -2 \\
\hline $\mathrm{SI} 3$ & I think the price of the treatment is too high. & -2 & $3 *$ & -3 & $5^{*}$ \\
\hline SI4 & I am afraid that the treatment will be too complicated. & 0 & $0 *$ & $5^{*}$ & $2^{*}$ \\
\hline SI5 & I am afraid of orthodontic treatment. & $2 *$ & 0 & -1 & -3 \\
\hline SI6 & I am worried that the treatment time will be excessively long. & $-I^{* *}$ & 4 & $2^{* *}$ & 5 \\
\hline SI7 & I think I am too old for orthodontic treatment. & 3 & I & $-2^{* *}$ & 3 \\
\hline SI8 & I cannot afford treatment. & $-I^{* *}$ & 2 & $-4^{* *}$ & I \\
\hline SI9 & $\begin{array}{l}\text { I am worried about orthodontic treatment because I do } \\
\text { not have enough knowledge in this area. }\end{array}$ & $4 * *$ & 2 & 1 & $-1 * *$ \\
\hline S20 & I have poor health and the treatment will make it worse. & -1 & -4 & $-4^{*}$ & -2 \\
\hline S2I & I never realized that my teeth are irregular. & $-2 * *$ & -5 & -4 & -5 \\
\hline S22 & I am afraid that this orthodontic technology may not be adequate. & -3 & $I^{* *}$ & -3 & -4 \\
\hline S23 & Other doctors do not recommend orthodontic treatment. & -5 & -4 & -5 & -3 \\
\hline S24 & My family and (or) friends object to the treatment. & -4 & $-I^{*}$ & -5 & $I^{*}$ \\
\hline S25 & I am afraid the treatment will affect my eating during the process. & $I^{* *}$ & $-3^{* *}$ & 4 & 3 \\
\hline S26 & I am worried that the treatment will be ineffective. & 5 & 4 & 0 & -1 \\
\hline S27 & I am worried that the treatment may have some side effects. & $3^{* *}$ & $5^{* *}$ & -2 & -3 \\
\hline S28 & I am afraid that the extraction will increase the space between my teeth. & $3 * *$ & $-3^{* *}$ & 0 & 0 \\
\hline S29 & $\begin{array}{l}\text { I am worried about that I am too old for treatment because } \\
\text { my teeth will get loose and fall off early. }\end{array}$ & 4 & 3 & $-I^{* *}$ & 4 \\
\hline S30 & I am afraid that the treatment will affect my future chewing and eating. & $4^{*}$ & $-1^{* *}$ & I & I \\
\hline S3I & I am afraid that my teeth will relapse and recur after treatment. & 5 & 4 & $I^{*}$ & $2 *$ \\
\hline S32 & I am worried about that after treatment I will lisp. & $2 * *$ & -1 & $0 *$ & -1 \\
\hline S33 & It is bothersome having to brush my teeth every time I finish eating. & $0 *$ & $-2^{* *}$ & $2 *$ & $4 *$ \\
\hline S34 & I am afraid that I will have nicknames because of the braces. & -5 & 0 & -2 & -5 \\
\hline S35 & I am afraid the treatment will cause me to lose appetite. & $I^{*}$ & $-5^{* *}$ & 2 & 2 \\
\hline S36 & I am worried that wearing braces will hurt my mouth. & 3 & $-2^{* *}$ & 3 & 2 \\
\hline S37 & I am afraid that I will not be able to speak perfectly with the braces. & I & I & $4 * *$ & 0 \\
\hline S38 & I am scared of dental procedures. & $2^{* *}$ & -1 & -3 & -2 \\
\hline S39 & I am worried that the braces will lower my chances of finding a partner. & $-3 * *$ & $5^{* *}$ & 0 & 0 \\
\hline S40 & I am afraid that food will remain stuck in my teeth after eating. & I & $-2^{* *}$ & I & $3^{*}$ \\
\hline S4I & I am afraid the treatment will affect my performance at work. & 0 & 0 & -1 & $-4 * *$ \\
\hline
\end{tabular}

Notes: *Distinguishing statement significant at $P<0.05$; **distinguishing statement significant at $P<0.01$.

orthodontic treatment procedures and the principle of orthodontic treatment. Patients' lack of information about orthodontic treatment or fear about pain and discomfort have been identified as causes of anxiety. ${ }^{10}$ Group 1 patients were in fear of orthodontic treatment and dental procedures. It has been reported that $45 \%$ of adults reported dental fear as a main reason for not undergoing dental treatment. ${ }^{24} \mathrm{With}$ such patients, orthodontists need to improve their communication 
and provide more information about orthodontic treatment procedures. Sergl et $\mathrm{al}^{25}$ believed that offering information about treatment may help patients achieve greater emotional control and perceive less discomfort during orthodontic treatment. Quality of care and attention are factors that have been found to be highly correlated with treatment-outcome satisfaction. ${ }^{5}$ A range of techniques may be applied for the nonpharmacological management of dental fear and anxiety. ${ }^{26}$ These techniques should always be based on understanding the situation with particular patients, their particular concerns, their individual backgrounds and experiences, and capacity for change.

Patients who loaded with factor 2 were all aged 24-30 years, and were single and childless. They wanted to make themselves appear more attractive through orthodontic treatment; ${ }^{16}$ however, they were worried that the braces would reduce their chances of finding a partner, and that the treatment could have certain sequelae. In the interviews, they expressed the wish to marry and have children within a few years. They cared a great deal about the benefits of orthodontic treatment with respect to verbal communication. If such patients are still unable to find partners despite having undergone orthodontic treatment, they may tend to put the blame on the braces or the orthodontist; they may not be satisfied with the orthodontic treatment even if the actual results are perfect. When dealing with such patients, orthodontists need to choose invisible appliances and verify that orthodontic treatment can indeed make the subjects look more physically attractive; however, orthodontists have to state that the treatment cannot help them find a partner or lower their chances of finding one. If this approach is followed, we believe that patients' adherence to treatment will be very good: they will not be worried that the treatment process may cause functional restrictions, discomfort, and pain (S6, S7, S25, S30, S33, S35, S36, and S40).

Patients who loaded with factor 3 were afraid that they would look unattractive with braces, that the treatment would be too complex, and that their speech would be imperfect with braces. These worries may have been related to the subjects' professions: there were two teachers, one trading manager, two salespersons, and one bank clerk. Those patients could afford to pay for the treatment, and they had to speak clearly and look presentable at work; however, they also lacked time to undergo treatment during clinical hours, and their workplaces were located far from hospital. They were very concerned about the opinions of other people. They were familiar with orthodontic treatment, and they were not worried that it could have some side effects. For such patients, orthodontists need to choose invisible appliances that do not affect pronunciation; they should also choose suitable appointment times and treatment plans to shorten the treatment time.

The perspectives related to factor 4 primarily concerned pain, cost, and dental hygiene. This group comprised three students, one unemployed person, and three recently hired employees. These patients thought that the price of treatment was excessive owing to their low income, and they were also worried about dental hygiene; however, they thought that brushing their teeth after eating was bothersome. These patients were afraid of pain during orthodontic treatment and tooth extraction. The prevalence of reported pain amounts to $95 \%$ among adults after initial arch-wire placement; the pain related to orthodontic appliances has been identified as the primary complaint among patients - being more serious in adults than in adolescents - and this discomfort is a major determining factor in avoiding orthodontic treatment. ${ }^{27}$ With such patients, orthodontists should provide more information about the details of orthodontic treatment and the pain involved. Following initial appliance placement, analgesics can alleviate pain; text messaging and telephone calls to patients have been found to result in decreased pain perception after initial arch-wire placement. ${ }^{28-30}$ Orthodontists need to promote education related to oral health care with such patients, and select appropriate appliances that the patients can afford.

\section{Limitations and future directions}

Some studies ${ }^{18,31}$ have clearly shown Q methodology to be a reliable, effective method for examining attitudes. However, the present study has a number of potential limitations. This study explored the perspectives and a range of viewpoints with respect to seeking orthodontic treatment in an adult female population in the PRC, and thus the results may not apply to other countries. Owing to the small convenience sampling employed, our results may not broadly relate to groups with different concerns. Q-sorting demands individual orientation before the sorting, and the time required in this study was 1 hour per individual. In future research, we will aim to combine results from different hospitals in the PRC as well as other countries. In this way, we will attempt to identify more universal factors that may deter adult patients from undergoing orthodontic treatment. We will try to select appropriate intervention measures to treat individuals according to their Q-sorting. In this way, we will compare differences in satisfaction, compliance, and anxiety among 
patients with those in a control group toward finding a new method to improve treatment outcomes and mental health during orthodontic treatment. We will also further examine the practicability of Q methodology.

\section{Conclusion}

The concerns of adult female individuals seeking orthodontic treatment are complex, and this study identified four typical characterizations that are associated with each perspective. Most adult female patients were worried about lack of information about orthodontic treatment and had dental fear. Q methodology is an appropriate, efficient tool to investigate the psychological characteristics of orthodontic patients. This study lays the groundwork for future research into the specific types of patient worries that may help orthodontists select the best strategies to help patients.

\section{Acknowledgments}

This work was supported by grants from Wenzhou Municipal Science and Technology Bureau (Y20130347). Thanks go to Dr Gerald Voliere for his kind help in improving the English in this paper.

\section{Disclosure}

The authors report no conflicts of interest in this work.

\section{References}

1. Cunningham SJ, Hunt NP. Quality of life and its importance in orthodontics. J Orthod. 2001;28:152-158.

2. Feu D, de Oliveira BH, de Oliveira Almeida MA, Kiyak HA, Miguel JA. Oral health-related quality of life and orthodontic treatment seeking. Am J Orthod Dentofacial Orthop. 2010;138:152-159.

3. Zhang M, McGrath C, Hägg U. The impact of malocclusion and its treatment on quality of life: a literature review. Int J Paediatr Dent. 2006;16: 381-287.

4. Hassan AH, Amin H. Association of orthodontic treatment needs and oral health-related quality of life in young adults. Am J Orthod Dentofacial Orthop. 2010;137:42-47.

5. Feldmann I. Satisfaction with orthodontic treatment outcome. Angle Orthod. 2014;84:581-587.

6. Sergl HG, Klages U, Zentner A. Functional and social discomfort during orthodontic treatment - effects on compliance and prediction of patients' adaptation by personality variables. Eur J Orthod. 2000;22: 307-315.

7. Doll GM, Zentner A, Klages U, Sergl HG. Relationship between patient discomfort, appliance acceptance and compliance in orthodontic therapy. J Orofac Orthop. 2000;61:398-413.

8. Gosney MB. An investigation into factors which may deter patients from undergoing orthodontic treatment. Br J Orthod. 1985;12:133-138.

9. Scheurer PA, Firestone AR, Burgin WB. Perception of pain as a result of orthodontic treatment with fixed appliances. Eur J Orthod. 1996;18: 349-357.
10. Sari Z, Uysal T, Karaman AL, Sargin N, Ure O. Does orthodontic treatment affect patients' and parents' anxiety levels? Eur J Orthod. 2005; 27:155-159.

11. Oliver RG, Knapman YM. Attitudes to orthodontic treatment. Br J Orthod. 1985;12:179-188.

12. Jones M, Chan C. The pain and discomfort during orthodontic treatment: a randomized controlled clinical trial of two aligning arch wires. Am J Orthod Dentofacial Orthop. 1992;102:373-381.

13. Khan RS, Horrocks EN. A study of adult orthodontic patients and their treatment. Br J Orthod. 1991;18:183-194.

14. Nattrass C, Sandy JR. Adult orthodontics - a review. Br J Orthod. 1995; 22:331-337.

15. Daniels AS, Seacat JD, Inglehart MR. Orthodontic treatment motivation and cooperation: a cross-sectional analysis of adolescent patients' and parents' responses. Am J Orthod Dentofacial Orthop. 2009;136: 780-787.

16. Pabari S, Moles DR, Cunningham SJ. Assessment of motivation and psychological characteristics of adult orthodontic patients. Am J Orthod Dentofacial Orthop. 2011;140:e263-e272.

17. Shinebourne P, Adams M. Q-methodology as a phenomenological research method. Existent Anal. 2007;18:103-116.

18. Brown SR. Political Subjectivity: Application Of Q-Methodology in Political Science. New Haven (CT): Yale University Press; 1980.

19. Watts S, Stenner P. Doing Q methodology: theory, method and interpretation. Qual Res Psychol. 2005;2:67-91.

20. Stephenson W. The Study of Behavior: Q-Technique and its Methodology. Chicago: University of Chicago Press; 1953.

21. Schabel BJ, McNamara JA Jr, Franchi L, Baccetti T. Q-sort assessment vs visual analog scale in the evaluation of smile esthetics. Am J Orthod Dentofacial Orthop. 2009;135:61-71.

22. Prabakaran R, Seymour S, Moles DR, Cunningham SJ. Motivation for orthodontic treatment investigated with Q-methodology: patients' and parents' perspectives. Am J Orthod Dentofacial Orthop. 2012;142: 213-220.

23. Amin Z. Q methodology - a journey into the subjectivity of human mind. Singapore Med J. 2000;41:410-414.

24. Todd J, Lader D. Adult Dental Health 1988 Survey. London: Her Majesty's Stationery Office; 1991.

25. Sergl HG, Klages U, Zentner A. Pain and discomfort during orthodontic treatment: causative factors and effects on compliance. Am J Orthod Dentofacial Orthop. 1998;114:684-691.

26. Armfield JM, Heaton LJ. Management of fear and anxiety in the dental clinic: a review. Aust Dent J. 2013;58:390-407.

27. Oliver RG, Knapman YM. Attitudes to orthodontic treatment. $B r J$ Orthod. 1985;12:179-188.

28. Ngan P, Wilson S, Shanfeld J, Amini H. The effect of ibuprofen on the level of discomfort in patients undergoing orthodontic treatment. Am J Orthod Dentofacial Orthop. 1994;106:88-95.

29. Bartlett BW, Firestone AR, Vig KW, Beck FM, Marucha PT. The influence of a structured telephone call on orthodontic pain and anxiety. Am J Orthod Dentofacial Orthop. 2005;128:435-441.

30. Keith DJ, Rinchuse DJ, Kennedy M, Zullo T. Effect of text message follow-up on patient's self-reported level of pain and anxiety. Angle Orthod. 2013;83:605-610.

31. Prasad RS. Development of the HIV/AIDS Q-sort instrument to measure physician attitudes. Fam Med. 2001;33:772-777. 
Patient Preference and Adherence

Dovepress

\section{Publish your work in this journal}

Patient Preference and Adherence is an international, peer-reviewed, open access journal that focuses on the growing importance of patient preference and adherence throughout the therapeutic continuum. Patient satisfaction, acceptability, quality of life, compliance, persistence and their role in developing new therapeutic modalities and compounds to optimize

Submit your manuscript here: http://www.dovepress.com/patient-preference-and-adherence-journa clinical outcomes for existing disease states are major areas of interest for the journal. This journal has been accepted for indexing on PubMed Central The manuscript management system is completely online and includes a very quick and fair peer-review system, which is all easy to use. Visit http://www. dovepress.com/testimonials.php to read real quotes from published authors. 